\title{
Erratum to: Geological setting and geochemical signatures of the mafic rocks from the Intra-Pontide Suture Zone: implications for the geodynamic reconstruction of the Mesozoic Neotethys
}

\author{
Kaan Sayit $^{1} \cdot$ Michele Marroni $^{2,3} \cdot$ M. Cemal Gönciüoglu ${ }^{1} \cdot$ Luca Pandolfi $^{2,3}$. \\ Alessandro Ellero $^{3} \cdot$ Giuseppe Ottria $^{3}$ - Chiara Frassi ${ }^{2}$
}

Published online: 23 December 2015

(C) Springer-Verlag Berlin Heidelberg 2015

\section{Erratum to: Int J Earth Sci (Geol Rundsch) DOI 10.1007/s00531-015-1202-2}

Unfortunately, Fig. 15 was wrongly published in the original publication of the article. The correct Fig. 15 is given below:
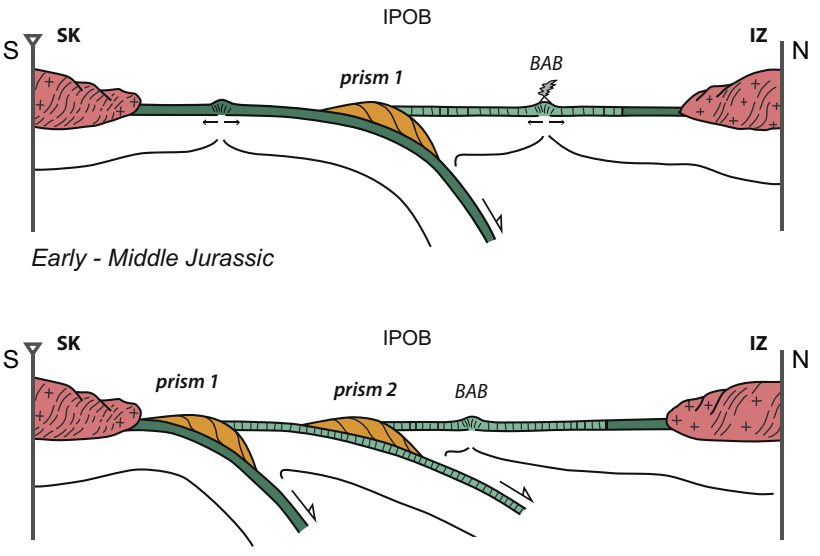

Late Jurassic - Early Cretaceous

ImIn SSZ oceanic crust

SK: Sakarya terrane

= MOR oceanic crust

IZ: Istanbul - Zonguldak terrane

= continental crust

IPOB: Intra-Pontide Oceanic basin

Fig. 15 Geodynamic reconstruction of the Intra-Pontide Oceanic domain during the Jurassic and Early Cretaceous. See text for further explanations

The online version of the original article can be found under doi:10.1007/s00531-015-1202-2.

Michele Marroni

marroni@dst.unipi.it

1 Department of Geological Engineering, Middle East

Technical University, Ankara, Turkey

2 Dipartimento di Scienze della Terra, Università di Pisa, Via

S. Maria, 53, 56126 Pisa, Italy

3 Istituto di Geoscienze e Georisorse, CNR, Pisa, Italy 